\section{A) Check for updates}

Cite this: Polym. Chem., 2017, 8 , 4856

\title{
Synthesis of well-defined epoxy-functional spherical nanoparticles by RAFT aqueous emulsion polymerization $\uparrow$
}

\author{
Fiona L. Hatton, (D) * Joseph R. Lovett and Steven P. Armes (DD *
}

The environmentally-friendly synthesis of epoxy-functional spherical nanoparticles has been achieved using polymerization-induced self-assembly (PISA) in aqueous solution. Firstly, a non-ionic hydrophilic stabilizer block, poly(glycerol monomethacrylate) (PGMA), was prepared by reversible addition-fragmentation chain transfer (RAFT) solution polymerization in ethanol. This water-soluble precursor was subsequently chain-extended via RAFT aqueous emulsion polymerization of glycidyl methacrylate (GlyMA) at $50{ }^{\circ} \mathrm{C}$ and neutral $\mathrm{pH}$ to ensure maximum retention of the epoxy functionality. PISA leads to the formation of well-defined PGMA-PGlyMA spherical diblock copolymer nanoparticles at up to $35 \% \mathrm{w} / \mathrm{w}$ solids and ${ }^{1} \mathrm{H}$ NMR spectroscopy studies indicated that virtually all of the epoxy groups survive such relatively mild conditions. DMF GPC studies confirmed that relatively low dispersities $\left(M_{w} / M_{n}<1.30\right)$ were obtained if the mean degree of polymerization of the core-forming PGlyMA block remained below 100 . Well-defined triblock copolymer nanoparticles could also be prepared via seeded RAFT emulsion polymerization of $n$-butyl methacrylate, with DMF GPC analysis indicating a relatively narrow molecular weight distribution $\left(M_{w} / M_{n}<1.20\right)$. The epoxy groups within the nanoparticle cores were ring-opened by adding sodium azide to a $10 \% \mathrm{~W} / \mathrm{W}$ aqueous copolymer dispersion at $50{ }^{\circ} \mathrm{C}$, as confirmed by $\mathrm{FT}$-IR spectroscopy. $\mathrm{PGMA}_{45}-\mathrm{PGlyMA}_{100}$ diblock copolymer nanoparticles could be conveniently converted into cationic nanogels by utilizing water-soluble diamines as crosslinkers. These nanogels were characterized by DLS and aqueous electrophoresis and remained intact when dispersed in DMF; in contrast, the corresponding linear precursor nanoparticles dissociated to form molecularly-dissolved copolymer chains under the

Received 4th July 2017 , Accepted 22nd July 2017 DOI: 10.1039/c7py01107e rsc.li/polymers \author{
same conditions.
}

\section{Introduction}

Homopolymerization or copolymerization of glycidyl methacrylate (GlyMA) has been widely reported using atom transfer radical polymerization, ${ }^{1}$ nitroxide-mediated polymerization ${ }^{2}$ or reversible addition-fragmentation chain transfer (RAFT) polymerization $^{3-5}$ to form well-defined statistical or diblock copolymers with high degrees of epoxy functionality. This approach enables a wide range of post-polymerization derivatizations with nucleophiles such as amines, hydroxyl groups, thiols, carboxylic acids or sodium azide. For example, the reaction of PGlyMA homopolymer with various secondary amines, sodium azide, or a thiol has been studied in DMSO, with high degrees of functionality being achieved within $2 \mathrm{~h}$ in most

Dainton Building, Department of Chemistry, University of Sheffield, Brook Hill, Sheffield, South Yorkshire S3 7HF, UK. E-mail: f.l.hatton@sheffield.ac.uk, s.p.armes@sheffield.ac.uk

$\dagger$ Electronic supplementary information (ESI) available. See DOI: 10.1039/ c7py01107e cases. ${ }^{5}$ Direct thiolation, bromination, iodination and phosphorylation of PGlyMA-based triblock copolymers has also been reported, although reaction times of up to $24 \mathrm{~h}$ were often required. ${ }^{6}$ Potential applications suggested for such derivatized GlyMA-based copolymers include gene and drug delivery, ${ }^{7}$ biocatalysis ${ }^{8}$ cell imaging, ${ }^{9}$ inkjet printing, ${ }^{10}$ chromatographic media, ${ }^{11}$ denitrogenation of petroleum feedstock, ${ }^{12}$ heavy metal absorbents ${ }^{13,14}$ and pressure-sensitive adhesives. ${ }^{15}$

GlyMA has also been utilized as a comonomer to prepare various types of epoxy-functional polymer colloids such as latexes ${ }^{16,17}$ microspheres ${ }^{18-20}$ anisotropic particles ${ }^{21}$ and microgels. ${ }^{22,23}$ For example, surfactant-free emulsion polymerization was used to prepare both poly(styrene-co-GlyMA) latexes containing surface epoxy groups and also core-shell latexes comprising polystyrene cores and poly(GlyMA-comethyl methacrylate) shells. ${ }^{16}$ Surfactant-free emulsion polymerization was also utilized to prepare crosslinked poly (styrene-co-GlyMA) particles, whose distinctive framboidal morphology was attributed to phase separation. ${ }^{24}$ Mesoporous silica nanoparticles have been modified via surface-initiated 
polymerization of GlyMA: post-polymerization crosslinking with cystamine afforded hybrid nanocarriers that could release encapsulated cargo through external stimuli such as a $\mathrm{pH}$ switch or the addition of glutathione. ${ }^{23}$ The self-assembly of GlyMA-based copolymers has also been reported, including the formation of micelles and reverse micelles, polymersomes (vesicles), organic-inorganic hybrid materials and polyion complexes. ${ }^{7}$ Surface-initiated polymerization has been used to prepare PGlyMA brushes with subsequent derivatization with octylamine. ${ }^{25}$ In related work, Klok and coworkers found that the presence of the tertiary amine methacrylate residues in P(GlyMA-co-2-(diethylamino)ethyl methacrylate) brushes resulted in enhanced rates of ring-opening when reacted with various amines. ${ }^{26}$

Organic nanoparticles prepared via block copolymer selfassembly have received growing attention. ${ }^{27}$ In particular, polymerization-induced self-assembly (PISA) has become recognized as a highly versatile technique that enables the efficient formation of a wide range of functional diblock copolymer nano-objects in various media utilizing many types of vinyl monomers. ${ }^{28-32}$ PISA involves chain extension of a soluble homopolymer with a second monomer that, once polymerized, becomes insoluble in the reaction media, thereby driving in situ self-assembly to form diblock copolymer nanoobjects. First reported in 2002 by Hawkett and coworkers, ${ }^{33}$ PISA was initially developed in the context of reversible addition-fragmentation chain transfer (RAFT) aqueous emulsion polymerization to prepare poly(acrylic acid)-poly( $n$-butyl acrylate) latexes ${ }^{34}$ and poly(acrylic acid)-polystyrene latexes. ${ }^{35}$ Subsequently, PISA has been extended to include various dispersion polymerization formulations conducted in either aqueous, ${ }^{36}$ alcoholic or non-polar media, ${ }^{32}$ while RAFT aqueous emulsion polymerization has continued to be explored by various groups. ${ }^{28,30,31,37-40}$ PISA formulations based on dispersion polymerization usually allow facile access to many nanoparticle morphologies, including spheres, worms and vesicles. ${ }^{36,41}$ In contrast, RAFT aqueous emulsion polymerizations often result in the formation of kinetically-trapped spheres, particularly for methacrylic core-forming blocks based on methyl methacrylate, ${ }^{42-45} n$-butyl methacrylate, ${ }^{46,47}$ benzyl methacrylate ${ }^{48}$ or 2,2,2-trifluoroethyl methacrylate. ${ }^{49,50}$ Nevertheless, the latter PISA formulations offer a potentially important route for the preparation of functional diblock copolymer nano-objects at up to $50 \% \mathrm{w} / \mathrm{w}$ solids, which represents a substantial improvement over traditional postpolymerization self-assembly techniques. ${ }^{30}$

We have previously reported using poly(glycerol monomethacrylate) (PGMA) as a steric stabilizer block for the preparation of diblock copolymer nano-objects via RAFT aqueous dispersion polymerization, ${ }^{30}$ RAFT alcoholic dispersion polymerization, ${ }^{36}$ and RAFT aqueous emulsion polymerization. ${ }^{48,49}$ In principle, PGMA can be obtained via reaction of PGlyMA with one equivalent of water, but this derivatization suffers from a cross-linking side reaction and in practice GMA is commercially available as a specialty monomer. However, the conversion of water-immiscible GlyMA into water-soluble
GMA can be readily achieved simply by heating an initial aqueous GlyMA emulsion at $80{ }^{\circ} \mathrm{C}$ for $8-9$ h. ${ }^{51}$ Remarkably, if this reaction is conducted at around neutral $\mathrm{pH}$ in the presence of air then no background polymerization occurs and no hydrolysis of the ester bond is detected. We have also reported using GlyMA as a comonomer in PISA syntheses to facilitate core cross-linking of block copolymer vesicles in order to improve their surfactant tolerance. ${ }^{52}$ A similar approach also works for cationic block copolymer worms, which were recently demonstrated to be 'superflocculants' for micrometersized silica particles. ${ }^{53}$ In both cases, the PISA synthesis involved statistical copolymerization of relatively low levels of GlyMA with 2-hydroxypropyl methacrylate. Subsequent crosslinking was achieved by adding either a diamine ${ }^{52}$ or 3-aminopropyltriethoxysilane (APTES). ${ }^{53,54}$ Of particular relevance to the present work, Tan et al. recently reported the photoinitiated RAFT dispersion polymerization of GlyMA in ethanolwater mixtures to form various copolymer morphologies. ${ }^{55}$ Other research teams have also incorporated relatively low amounts of GlyMA during PISA to introduce desired functionality. For example, Esser $e t$ al. conjugated a gadolinium chelate to an epoxy-functional stabilizer block for MRI imaging. ${ }^{56}$

Herein we report the highly convenient and environmentally-friendly PISA synthesis of epoxy-functional spherical diblock copolymer nanoparticles via RAFT aqueous emulsion polymerization of GlyMA. Systematic variation of the radical initiator type, reaction temperature and solution $\mathrm{pH}$ enabled optimum reaction conditions to be identified that preserved virtually all of the original epoxy groups on the time scale of the PISA synthesis. The block copolymer chains were characterized by ${ }^{1} \mathrm{H}$ NMR spectroscopy and GPC, while TEM and DLS were used to characterize the particle size and morphology of the resulting nanoparticles. The epoxy groups were subsequently reacted with either sodium azide or model diamines. The latter reagents produced highly crosslinked primary amine-based nanogels with appreciable cationic character, as confirmed by aqueous electrophoresis studies.

\section{Experimental}

\section{Materials}

Glycerol monomethacrylate (GMA; >99\%) was donated by GEO Specialty Chemicals (Hythe, UK) and used without further purification. Glycidyl methacrylate (GlyMA; 97\%), n-butyl methacrylate (BuMA; 99\%), 4,4'-azobis(4-cyanopentanoic acid) (ACVA; 99\%), sodium azide ( $\geq 99.5 \%)$, ethylenediamine (EDA; 99\%), bis(3-aminopropyl)terminated poly(ethylene oxide) $\left(\mathrm{PEG}_{31} \mathrm{DA} ; M_{\mathrm{n}} \approx 1500 \mathrm{~g} \mathrm{~mol}^{-1}\right)$ and tert-butyl hydroperoxide (TBH; 70\% $\mathrm{H}_{2} \mathrm{O}$ solution) were purchased from Sigma-Aldrich UK. 2,2'-Azobis[2-(2-imidazolin-2-yl)propane]dihydrochloride (VA-044; $\geq 97 \%$ ) was purchased from Wako Chemicals GmBH. Sodium sulphite $\left(\mathrm{Na}_{2} \mathrm{SO}_{3} ; 98 \%\right)$ was purchased from Alfa Aesar UK and 2-cyano-2-propyl dithiobenzoate (CPDB) was purchased from STREM Chemicals Ltd (Cambridge, UK). Ammonium chloride ( $\geq 99 \%)$, hydrochloric acid $(35 \%)$ and 
sodium hydroxide (98\%) were obtained from VWR Chemicals UK. All chemicals were used as received, unless otherwise stated. $d_{6}$-DMSO was purchased from Goss Scientific Instruments Ltd (Cheshire, UK). All other solvents were purchased from Fisher Scientific (Loughborough, UK) and used as received. Deionized water was used for all aqueous experiments. Dialysis tubing used in this study was standard-grade regenerated cellulose with molecular weight cut-off values of 1 and $50 \mathrm{kDa}$, purchased from Spectrum Laboratories, Inc. (Rancho Dominguez CA, USA).

\section{Characterisation}

${ }^{1} \mathbf{H}$ NMR spectroscopy. Spectra were recorded at $20{ }^{\circ} \mathrm{C}$ in $d_{6^{-}}$ DMSO using a Bruker Avance III HD 400 spectrometer operating at 400.23 MHz. Selected spectra were recorded with solvent suppression utilized a 4 seconds presaturation pulse and spoil gradient.

Dynamic light scattering (DLS). A Malvern Zetasizer NanoZS instrument $\left(\right.$ scattering angle $=173^{\circ}$ ) was use to record hydrodynamic diameters $\left(D_{\mathrm{h}}\right)$ and polydispersity indices (PDI) via the cumulants method. All measurements were conducted on $0.1 \% \mathrm{w} / \mathrm{w}$ copolymer dispersions in deionized water at $25{ }^{\circ} \mathrm{C}$ with $120 \mathrm{~s}$ equilibration time, using disposable plastic cuvettes, or in DMF using glass cuvettes. Data were averaged over three consecutive measurements, comprising a minimum of ten runs per measurement. The standard deviation for each hydrodynamic diameter was calculated from the PDI.

Aqueous electrophoresis. Zeta potentials were determined as a function of solution $\mathrm{pH}$ using a Malvern Zetasizer NanoZS instrument equipped with an auto-titrator for diblock copolymer nanoparticles diluted to approximately $0.3 \% \mathrm{w} / \mathrm{w}$ using $1 \mathrm{mM} \mathrm{NaCl}$ as background electrolyte. The solution $\mathrm{pH}$ was adjusted using $\mathrm{NaOH}$ or $\mathrm{HCl}$. Data were averaged over three consecutive measurements, comprising a minimum of ten runs per measurement.

Gel permeation chromatography (GPC). The number-average molecular weights $\left(M_{\mathrm{n}}\right)$, weight-average molecular weights $\left(M_{\mathrm{w}}\right)$ and dispersities $\left(M_{\mathrm{w}} / M_{\mathrm{n}}\right)$ were assessed using a DMF GPC instrument comprising two Agilent PL gel $5 \mu \mathrm{m}$ Mixed-C columns and a guard column connected in series to an Agilent 1260 Infinity GPC system equipped with both refractive index and UV-visible detectors (only the refractive index detector was used in these experiments) operating at $60^{\circ} \mathrm{C}$. The GPC eluent was HPLC-grade DMF containing $10 \mathrm{mM} \mathrm{LiBr}$ at a flow rate of $1.0 \mathrm{~mL} \mathrm{~min}^{-1}$. DMSO was used as a flow-rate marker. Calibration was achieved using a series of ten near-monodisperse poly(methyl methacrylate) standards (ranging in $M_{\mathrm{p}}$ from 625 to $618000 \mathrm{~g} \mathrm{~mol}^{-1}$ ). Chromatograms were analyzed using Agilent GPC/SEC software.

Transmission electron microscopy (TEM). Copper/palladium TEM grids (Agar Scientific, UK) were coated in-house to yield a thin film of amorphous carbon. The grids were subjected to a glow discharge for $30 \mathrm{~s}$. Aqueous droplets of copolymer dispersions $(10.0 \mu \mathrm{L}, 0.1 \% \mathrm{w} / \mathrm{w})$ were placed on freshly-treated grids for $1 \mathrm{~min}$ and then carefully blotted with filter paper to remove excess solution. To ensure sufficient electron contrast, a $10.0 \mu \mathrm{L}$ aqueous droplet of a $0.75 \% \mathrm{w} / \mathrm{w}$ uranyl formate solution was then placed on the sample-loaded grid for $20 \mathrm{~s}$ and blotted to remove excess stain. Each grid was then carefully dried using a vacuum hose. Imaging was performed at $80 \mathrm{kV}$ using a FEI Tecnai Spirit 2 microscope fitted with an Orius SC1000B camera.

Elemental microanalysis. Carbon, hydrogen and nitrogen contents of freeze-dried copolymers were determined in-house using a Vario MICRO Cube CHN/S analyzer (detection limit = $0.30 \%)$.

Fourier transform infrared (FT-IR) spectroscopy. Spectra were recorded for freeze-dried copolymers at $20{ }^{\circ} \mathrm{C}$ (256 scans accumulated per spectrum) using a Thermo-Scientific Nicolet IS10 FT-IR spectrometer equipped with a Golden Gate Diamond ATR accessory.

\section{Synthesis of PGMA 45 macro-CTA by RAFT solution polymeriz- ation in ethanol}

A PGMA $_{45}$ macro-CTA was prepared as previously described. ${ }^{57}$ Briefly, CPDB (1.21 g, $4.37 \mathrm{mmol}$ ), GMA (50.0 g, $0.312 \mathrm{~mol}$ ) and ethanol $(78.6 \mathrm{~g}, 60 \% \mathrm{w} / \mathrm{w})$ were weighed into a round-bottomed flask. ACVA initiator $(245 \mathrm{mg}, 0.874 \mathrm{mmol}, \mathrm{CPDB} / \mathrm{ACVA}=$ 5.0) was added and the reaction mixture was degassed with $\mathrm{N}_{2}$ in an ice bath for 40 min prior to placing the flask in an oil bath set at $70{ }^{\circ} \mathrm{C}$. The polymerization was quenched after 160 min after the GMA conversion had reached 63\%. The crude macro-CTA was diluted with methanol and precipitated into excess dichloromethane (twice) to remove unreacted GMA monomer and other impurities. The mean DP of the purified $\mathrm{PGMA}_{45}$ macro-CTA was confirmed to be 45 by ${ }^{1} \mathrm{H}$ NMR endgroup analysis by comparing the integrated aromatic protons at 7.4-7.9 ppm assigned to the dithiobenzoate chain-ends to the GMA pendant proton signals $\left(-\mathrm{C}_{2}-\mathrm{C} \underline{H}(\mathrm{OH})-\underline{\mathrm{C}}_{2} \mathrm{OH}\right)$ at 3.4-4.3 ppm and methacrylate backbone signals $\left(-\mathrm{C}_{2}-\mathrm{C}\right.$ $\left.\left(\mathrm{C}_{3}\right)^{-}\right)$at $0.7-2.5 \mathrm{ppm}$.

Synthesis of PGMA PG $_{4}$-PGMMA $n$ nanoparticles by RAFT aqueous emulsion polymerization

The synthesis of $\mathrm{PGMA}_{45}-\mathrm{PGlyMA}_{100}$ is representative of the general protocol. PGMA $_{45}$ macro-CTA $(1.20 \mathrm{~g}, 0.162 \mathrm{mmol}$ ), and deionized water $(31.58 \mathrm{~g})$ were weighed into a $100 \mathrm{~mL}$ round-bottomed flask to target a final solids content of $10 \%$ w/w. VA-044 initiator $(13.0 \mathrm{mg}, 0.0404 \mathrm{mmol}$, macro-CTA/ VA-044 $=4.0$ ) was added and the solution $\mathrm{pH}$ was adjusted to $\mathrm{pH} 7.0-7.5$ by addition of either 0.1 or $0.01 \mathrm{M} \mathrm{NaOH}$. GlyMA $(2.30 \mathrm{~g}, 16.2 \mathrm{mmol})$ was added and the reaction mixture was degassed with $\mathrm{N}_{2}$ in an ice bath for $30 \mathrm{~min}$, before placing in an oil bath at $50{ }^{\circ} \mathrm{C}$. The GlyMA polymerization was quenched by removal from the oil bath after $1 \mathrm{~h}$, followed by exposure to air. The copolymer chains were analyzed by ${ }^{1} \mathrm{H}$ NMR and GPC while the copolymer nanoparticles were characterized by TEM, DLS and aqueous electrophoresis.

\section{Synthesis of PGMA 45 -PGlyMA $25-$ PBuMA $_{75}$ triblock copolymer by seeded RAFT aqueous emulsion polymerization}

The PGMA $_{45}-$ PGlyMA $_{25}-\mathrm{PBuMA}_{75}$ triblock copolymer was prepared by in situ chain extension of $\mathrm{PGMA}_{45}-\mathrm{PGlyMA}_{25}$ nano- 
particles using BuMA. PGMA 45 macro-CTA $(0.15 \mathrm{~g}, 20.2 \mu \mathrm{mol})$, and deionized water $(2.01 \mathrm{~g})$ were weighed into a vial to give a final target solids content of $10 \% \mathrm{w} / \mathrm{w}$. VA-044 initiator (0.16 mg, $5.05 \mu \mathrm{mol}$, macro-CTA/VA-044 = 4.0) was added using a freshly prepared stock solution $(163 \mu \mathrm{L}, 0.03 \mathrm{M}$ VA-044 stock solution) and the solution $\mathrm{pH}$ was adjusted to $\mathrm{pH}$ 7.0-7.5 using 0.01 M NaOH. GlyMA (0.072 g, $0.50 \mathrm{mmol}$ ) was added to the vial prior to degassing the reaction mixture with $\mathrm{N}_{2}$ in an ice bath for $30 \mathrm{~min}$, after which the vial was placed in an oil bath at $50{ }^{\circ} \mathrm{C}$. Aliquots were extracted for ${ }^{1} \mathrm{H}$ NMR and GPC analyses after $1 \mathrm{~h}$, then degassed BuMA (0.215 g, $1.50 \mathrm{mmol}$ ) was added via syringe and the aqueous dispersion was stirred at $50{ }^{\circ} \mathrm{C}$ for a further $3 \mathrm{~h}$. The BuMA polymerization was quenched by removing the reaction vessel from the oil bath followed by exposure to air. The copolymer chains were analyzed by ${ }^{1} \mathrm{H}$ NMR and GPC while the copolymer nanoparticles were characterized by TEM, DLS and aqueous electrophoresis. For the preparation of the corresponding statistical diblock copolymer, the BuMA (0.215 g, $1.50 \mathrm{mmol})$ was added at the same time as the GlyMA $(0.072 \mathrm{~g}$, $0.50 \mathrm{mmol}$ ) followed by degassing of the comonomer mixture using nitrogen.

\section{Derivatization of PGMA PG $_{45}$-PGMA 100 nanoparticles and dis- solved chains using sodium azide}

$\mathrm{PGMA}_{45}-\mathrm{PGlyMA}_{100}$ nanoparticles were prepared at $20 \% \mathrm{w} / \mathrm{w}$ solids and diluted to $10 \% \mathrm{w} / \mathrm{w}$ solids using deionized water. For the DMF scoping experiment, the $\mathrm{PGMA}_{45}-\mathrm{PGlyMA}_{100}$ nanoparticle dispersion was freeze-dried and then redissolved in $\mathrm{DMF}$ at a copolymer concentration of $3.5 \% \mathrm{w} / \mathrm{w}$. For an aqueous $\mathrm{PGMA}_{45}-\mathrm{PGlyMA}_{100}$ nanoparticle dispersion $(2.0 \mathrm{~mL}$, $10 \% \mathrm{w} / \mathrm{w}$, containing $1.15 \mathrm{mmol}$ epoxy groups), $\mathrm{NaN}_{3}(150 \mathrm{mg}$, $2.30 \mathrm{mmol})$ and $\mathrm{NH}_{4} \mathrm{Cl}(123 \mathrm{mg}, 2.30 \mathrm{mmol})$ were added and the ring-opening reaction was allowed to proceed for $24 \mathrm{~h}$ at either $20^{\circ} \mathrm{C}$ or at $50{ }^{\circ} \mathrm{C}$ using an oil bath. Subsequently, the aqueous dispersions or DMF solution were purified by dialysis (molecular weight cut-off $=1 \mathrm{kDa}$ ) against deionized water and freeze-dried for FT-IR spectroscopy studies and elemental microanalysis. Such copolymers were also redissolved in $d_{6}$ DMSO for ${ }^{1} \mathrm{H}$ NMR analysis. A control experiment was also performed in the absence of $\mathrm{NH}_{4} \mathrm{Cl}$ in the case of the aqueous copolymer dispersion derivatization.

\section{Diamine crosslinking of PGMA PF-PGlyMA $_{100}$ nanoparticles}

A $20 \% \mathrm{w} / \mathrm{W}$ aqueous dispersion of $\mathrm{PGMA}_{45}-\mathrm{PGlyMA}_{100}$ nanoparticles was diluted to $10 \% \mathrm{w} / \mathrm{w}$ solids using deionized water. Each diamine was weighed into a vial and a known volume of the copolymer dispersion $(2.0 \mathrm{~mL}, 10 \% \mathrm{w} / \mathrm{w}, 1.15 \mathrm{mmol}$ epoxy groups) was added, following which each sample vial was placed on a roller mixer for $24 \mathrm{~h}$ at $20^{\circ} \mathrm{C}$. Each copolymer dispersion was then dialyzed against deionized water using regenerated cellulose dialysis tubing (molecular weight cut-off = $50 \mathrm{kDa}$ ) to remove any free unreacted diamine. Following dialysis, 1.0-2.0 $\mathrm{mL}$ of the purified copolymer dispersions were freeze-dried for elemental microanalyses and FT-IR spectroscopy studies.

\section{Results and discussion}

First, a PGMA 45 macro-CTA was synthesized by RAFT solution polymerization of GMA in ethanol at $70{ }^{\circ} \mathrm{C}$, as previously described. ${ }^{57}$ The resulting purified PGMA $_{45}$ macro-CTA was subsequently chain-extended via RAFT aqueous emulsion polymerization of GlyMA. The synthesis parameters employed for this PISA formulation were systematically varied while targeting a constant diblock copolymer composition $\left(\mathrm{PGMA}_{45}{ }^{-}\right.$ PGlyMA $_{100}$ ) in order to identify the optimum reaction conditions required to preserve the epoxy functionality, see Table 1. In principle, epoxy groups can be ring-opened via nucleophilic attack by either water or a hydroxyl group (which may be located on the PGMA stabilizer chains or formed

Table 1 Summary of monomer conversions and molecular weight data obtained for the synthesis of a series of PGMA $45-P G l y M A_{100}$ diblock copolymer nanoparticles at $10 \% \mathrm{w} / \mathrm{w}$ solids via RAFT aqueous emulsion polymerization of GlyMA using a PGMA 45 macro-CTA under various reaction conditions

\begin{tabular}{|c|c|c|c|c|c|c|c|}
\hline Entry number & Initiator type ${ }^{a}$ & Temperature $\left({ }^{\circ} \mathrm{C}\right)$ & Solution $\mathrm{pH}$ & Reaction time $^{d}(\mathrm{~h})$ & $M_{\mathrm{n}}^{e}\left(\mathrm{~g} \mathrm{~mol}^{-1}\right)$ & $M_{\mathrm{w}}^{e}\left(\mathrm{~g} \mathrm{~mol}^{-1}\right)$ & $M_{\mathrm{w}} / M_{\mathrm{n}}{ }^{e}$ \\
\hline 2 & ACVA & 70 & 5.2 & 2.0 & 29800 & 41500 & 1.39 \\
\hline 5 & VA-044 & 40 & 4.5 & 1.0 & 23400 & 36700 & 1.57 \\
\hline 6 & VA-044 & 40 & 7.2 & 1.0 & 24000 & 37500 & 1.56 \\
\hline 7 & VA-044 & 50 & 4.2 & 1.0 & 23900 & 29200 & 1.22 \\
\hline 10 & VA-044 & 50 & 7.1 & 2.0 & 24600 & 32400 & 1.32 \\
\hline 11 & $t \mathrm{BH} / \mathrm{Na}_{2} \mathrm{SO}_{3}{ }^{b}$ & 30 & 3.1 & 2.5 & 24500 & 48800 & 1.99 \\
\hline 12 & $t \mathrm{BH} / \mathrm{Na}_{2} \mathrm{SO}_{3}{ }^{c}$ & 30 & 3.0 & 2.5 & 25200 & 46700 & 1.85 \\
\hline
\end{tabular}

${ }^{a} \mathrm{PGMA}_{45} \mathrm{CTA} /$ initiator molar ratio $=4.0$, unless otherwise stated. ${ }^{b} \mathrm{PGMA}_{45} \mathrm{CTA} / \mathrm{TBH}-\mathrm{Na}_{2} \mathrm{SO}_{3}$ molar ratio $=10 .{ }^{c} \mathrm{PGMA}_{45} \mathrm{CTA} / \mathrm{TBH}-\mathrm{Na} \mathrm{SO}_{3}$ molar ratio $=5 .{ }^{d}$ Monomer conversion reached more than $98 \%$ for all entries, as determined by ${ }^{1} \mathrm{H}$ NMR analysis in $d_{6}$-DMSO. ${ }^{e}$ Determined by gel permeation chromatography using DMF containing $10 \mathrm{mM} \mathrm{LiBr}$ as eluent and calibrated using a series of near-monodisperse poly(methyl methacrylate) standards. 
in situ after initial reaction of GlyMA residues with water). In the latter case, intermolecular reaction can result in chain branching and hence broadening of the molecular weight distribution. In principle, conducting the RAFT aqueous emulsion polymerization of GlyMA at lower temperatures, for shorter reaction times, and at neutral $\mathrm{pH}$ should suppress ring-opening side-reactions. The two azo initiators investigated in this initial set of experiments, ACVA and VA-044, have $10 \mathrm{~h}$ half-lives of 69 and $44{ }^{\circ} \mathrm{C}$ respectively in water. In addition, a tert-butyl hydroperoxide-sodium sulfite $\left(\mathrm{TBH}-\mathrm{Na}_{2} \mathrm{SO}_{3}\right)$ redox couple was also examined to enable these PISA syntheses to be conducted at $30^{\circ} \mathrm{C}$. Indeed, GlyMA polymerizations conducted using ACVA at $70{ }^{\circ} \mathrm{C}$ resulted in relatively broad molecular weight distributions $\left(M_{\mathrm{w}} / M_{\mathrm{n}}=1.34-1.50\right)$ (Table 1, entries 1-4). Perhaps surprisingly, syntheses conducted at $40{ }^{\circ} \mathrm{C}$ using VA-044 (Table 1, entries 5 and 6) yielded similar results, while the redox-initiated polymerizations performed at $30{ }^{\circ} \mathrm{C}$ actually gave the highest dispersities (Table 1, entries 11 and 12).

Notably, employing VA-044 at $50{ }^{\circ} \mathrm{C}$ produced relatively narrow molecular weight distributions at both $\mathrm{pH} 4$ and $\mathrm{pH} 7$, particularly for shorter reaction times (entries 7-10). In all cases, monomer conversion exceeded $98 \%$ within $1.0 \mathrm{~h}$ as determined by ${ }^{1} \mathrm{H}$ NMR analysis, with longer reaction times merely leading to broader molecular weight distributions. Thus, intermolecular side-reactions can be suppressed simply by minimizing the reaction time without having any deleter- ious effect on the monomer conversion. Henceforth, all further PISA syntheses were conducted for just $1.0 \mathrm{~h}$ at $50{ }^{\circ} \mathrm{C}$ using VA-044 $\left(\mathrm{PGMA}_{45} \mathrm{CTA} / \mathrm{VA}-044=4.0\right)$ at a solution $\mathrm{pH}$ of approximately 7.0, see Scheme 1 . Under such conditions, the potential loss of epoxy functionality during GlyMA polymerization was investigated by ${ }^{1} \mathrm{H}$ NMR spectroscopy, employing 3-(trimethylsilyl) propionic acid (TMSP) as an internal standard (see Fig. S1 $\dagger$ ). Comparison of the integrated epoxy proton signals at 2.7 and $2.8 \mathrm{ppm}$ with the TMSP signals located at $0.0 \mathrm{ppm}$ indicated that minimal $(<1 \%)$ ring-opening occurred under the above optimized conditions when targeting PGMA $_{45}$-PGlyMA 100 .

Following these initial studies, the kinetics of the RAFT aqueous emulsion polymerization of GlyMA was investigated when targeting $\mathrm{PGMA}_{45}-\mathrm{PGlyMA}_{100}$, see Fig. 1. The reaction solution was periodically sampled throughout the GlyMA polymerization and aliquots were diluted using $d_{6}$-DMSO for ${ }^{1} \mathrm{H}$ NMR analysis and DMF for GPC analysis; this ensures molecular dissolution of the copolymer chains in each case. The PGMA $_{45}$ CTA/VA-044 molar ratio was varied from 2.0 to 8.0 at a fixed $\mathrm{PGMA}_{45}$ CTA concentration. As expected, faster polymerizations were observed when using a higher VA-044 concentration, with more than 99\% conversion being attained within $30 \mathrm{~min}$ at $50^{\circ} \mathrm{C}$ for a $\mathrm{PGMA}_{45} \mathrm{CTA} / \mathrm{VA}-044$ molar ratio of 2.0. DMF GPC analysis revealed a linear increase in numberaverage molecular weight $\left(M_{\mathrm{n}}\right)$ with monomer conversion,
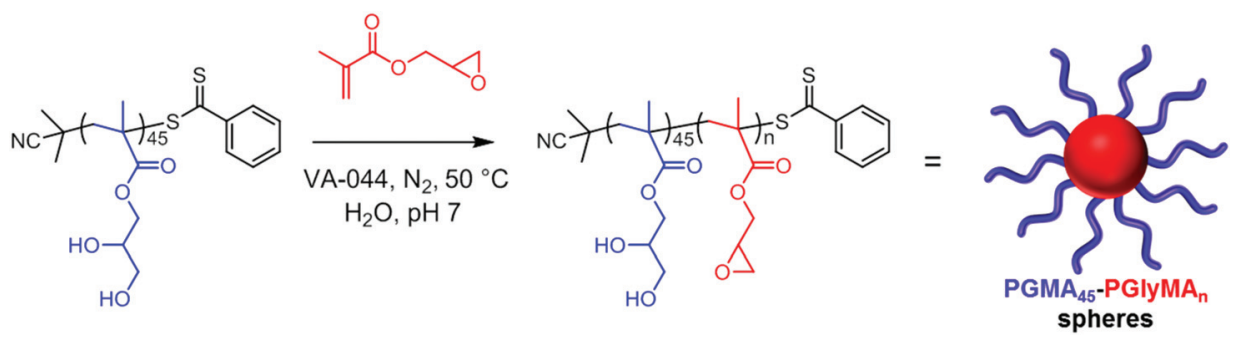

Scheme 1 Schematic representation of the chain extension of a PGMA 45 macro-CTA via RAFT aqueous emulsion polymerization of GlyMA.
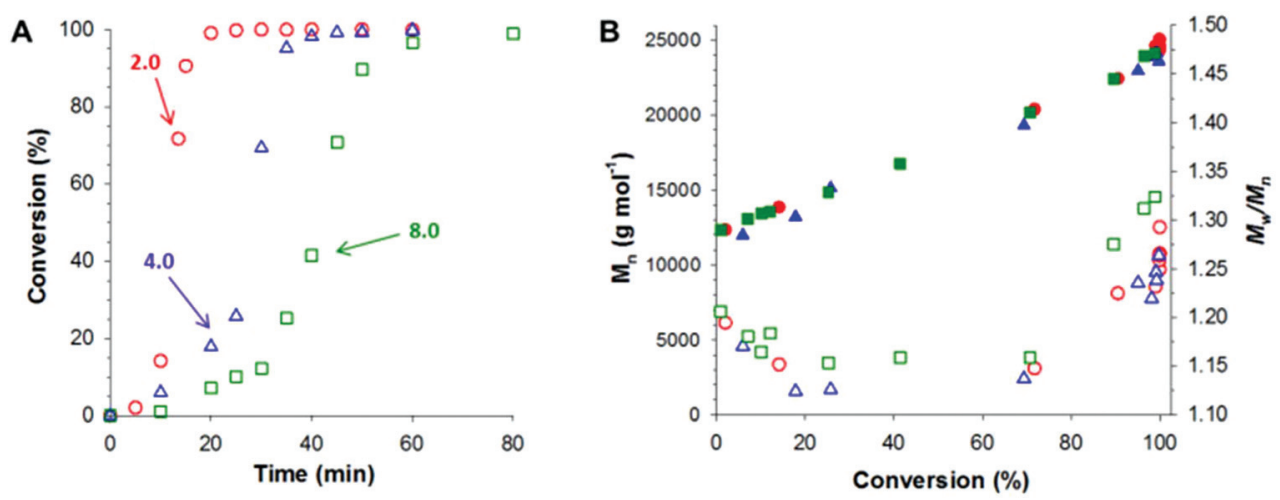

Fig. 1 Kinetics of the RAFT aqueous emulsion polymerization of GlyMA at $50{ }^{\circ} \mathrm{C}$. These PISA syntheses were conducted at $10 \% \mathrm{w} / \mathrm{w}$ solids and a solution $\mathrm{pH}$ of 7.0-7.5. The PGMA 45 macro-CTA/VA-044 molar ratio was varied from 2.0 (red circles) to 4.0 (blue triangles) to 8.0 (green squares). (A) Conversion vs. time curves obtained from ${ }^{1} \mathrm{H}$ NMR studies. (B) Evolution of $M_{\mathrm{n}}$ (closed symbols) and $M_{\mathrm{w}} / M_{\mathrm{n}}$ (open symbols) with monomer conversion. The target copolymer composition was $\mathrm{PGMA}_{45}-\mathrm{PGlyMA}_{100}$ in each case. 
while dispersities $\left(M_{\mathrm{w}} / M_{\mathrm{n}}\right)$ remained below 1.35 in all cases. Perhaps surprisingly, using a PGMA $_{45}$ CTA/VA-044 molar ratio of 4.0 resulted in the lowest final $M_{\mathrm{w}} / M_{\mathrm{n}}$ of 1.26 . Previous studies have shown that increasing the CTA/initiator molar ratio usually reduces the dispersity. ${ }^{48}$ Presumably, the slightly higher final dispersity $\left(M_{\mathrm{w}} / M_{\mathrm{n}}=1.32\right)$ obtained when employing a PGMA $_{45}$ CTA/VA-044 molar ratio of 8.0 indicates that some degree of latent branching via epoxy ring-opening occurs over the longer time scale required for approximately full conversion (80 min vs. 40 min; see Fig. 1A).

Varying the target degree of polymerization (DP) of the core-forming PGlyMA block from 35 to 300 resulted in the formation of a series of sterically-stabilized nanoparticles of increasing size, as judged by dynamic light scattering (DLS) and transmission electron microscopy (TEM) studies, see Fig. 2 and Table S1. $\dagger$ For relatively short core-forming block DPs $(\leq 100)$, the former technique indicated narrow particle size distributions (PDI $<0.10$ ), with mean particle diameters ranging from 20 to $40 \mathrm{~nm}$. Targeting longer PGlyMA blocks $(100<\mathrm{DP}<300)$ produced less uniform nanoparticles with hydrodynamic diameters of up to $462 \mathrm{~nm}$. TEM studies confirmed an exclusively spherical morphology in all cases. However, this technique revealed the presence of much smaller particles than those indicated by DLS, suggesting incipient aggregation. This is consistent with the much broader size distributions observed when targeting higher PGlyMA DPs (e.g. $\mathrm{DP}=300)$. This is illustrated in the data set shown in
Fig. 2A, where the error bars represent the width of each particle size distribution, rather than the experimental error. There is also a discernible change in gradient at a PGlyMA DP of approximately 100, which appears to correspond to the onset of flocculation. Further TEM images of other $\mathrm{PGMA}_{45}$ $\mathrm{PGlyMA}_{n}$ nanoparticles support this hypothesis, see Fig. S2. $\dagger$ Furthermore, targeting PGlyMA DPs of more than 400 led to visible signs of macroscopic precipitation. Subsequent analysis of such failed PISA syntheses confirmed the presence of large aggregates comprising spherical nanoparticles, see Fig. S3. $\dagger$ We do not have a satisfactory explanation for this unexpectedly low upper limit DP: we have been able to target much longer core-forming blocks for other aqueous PISA syntheses using PGMA stabilizer blocks with similar DPs without significant nanoparticle aggregation. ${ }^{48,58,59}$

DMF GPC analyses indicate that relatively low dispersities $\left(M_{\mathrm{w}} / M_{\mathrm{n}}<1.30\right)$ were obtained when targeting PGlyMA DPs of up to 100 (Fig. 3 and Table S1 $\dagger$ ). Given the well-known propensity of GlyMA residues to undergo intermolecular crosslinking reactions in the presence of water and/or other hydroxyl-functional polymers such as PGMA, ${ }^{52}$ we were pleasantly surprised by these observations. However, increasing the core-forming block DP above 100 led to a dramatic broadening in the molecular weight distribution $\left(M_{\mathrm{w}} / M_{\mathrm{n}}=1.44\right.$ to 1.85$)$. Inspecting the relevant chromatograms reveals substantial tailing to higher molecular weight, which is most obvious for the PGMA $_{45}-$ PGlyMA $_{400}$ diblock copolymer (Fig. 3 and also
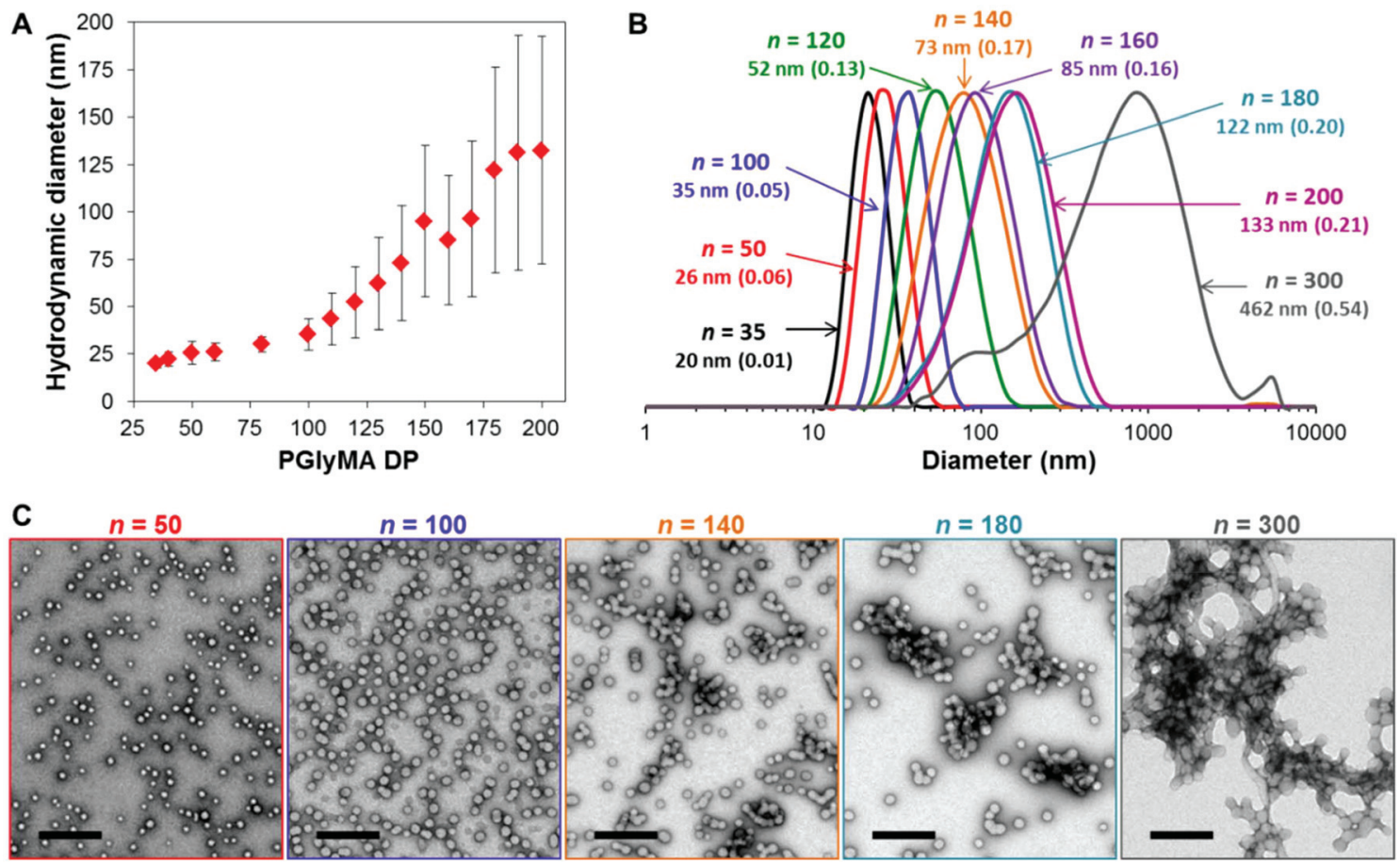

Fig. 2 (A) Relationship between DLS diameter $\left(D_{h}\right)$ and target PGlyMA DP for a series of PGMA $45-$ PGlyMA $A_{n}$ diblock copolymer nanoparticles prepared by RAFT aqueous emulsion polymerization of GlyMA at $10 \% \mathrm{w} / \mathrm{w}$ solids; error bars indicate the standard deviations for each particle size distribution, rather than the experimental error. (B) Selected DLS intensity-average size distributions, with $D_{\mathrm{h}}$ and PDI indicated, and (C) TEM images of representative samples, where $n$ indicates the mean DP of the core-forming PGlyMA block. Scale bars represent $200 \mathrm{~nm}$ in all five images. 


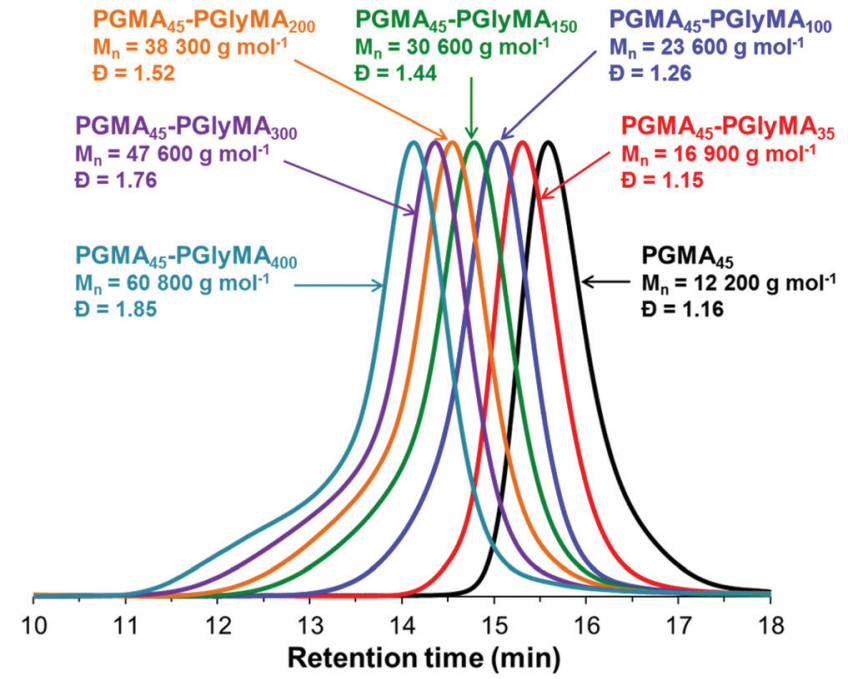

Fig. 3 Overlaid GPC chromatograms obtained for $\mathrm{PGMA}_{45}-\mathrm{PGlyMA}_{n}$ diblock copolymers prepared by aqueous RAFT emulsion polymerization of GlyMA at $50{ }^{\circ} \mathrm{C}$ and $10 \%$ w/w solids, where the mean DP for the coreforming PGlyMA block $(n)=35,100,150,200,300$ or 400 .

Table S1†). This feature is consistent with increasing levels of light branching. ${ }^{60,61}$ Nevertheless, blocking efficiencies were high in all cases, with little or no evidence for unreacted $\mathrm{PGMA}_{45}$ macro-CTA. The pseudo-living character of such RAFT aqueous emulsion polymerizations was confirmed by a 'selfblocking' experiment, see Fig. S4. $\dagger$

Thus a just-nucleated PGMA $_{45}-\mathrm{PGlyMA}_{25}$ precursor prepared by RAFT aqueous emulsion polymerization was used as a seed and chain-extended by a further 75 GlyMA units. This second-stage polymerization proceeded to more than $99 \%$, yielding PGMA $_{45}-$ PGlyMA $_{100}$ with a unimodal molecular weight distribution and a final $M_{\mathrm{w}} / M_{\mathrm{n}}$ of 1.20 (Fig. S4†). For RAFT aqueous dispersion polymerizations, Blanazs et al. have shown that a relatively high copolymer concentration is an important parameter for the formation of higher order morphologies. ${ }^{57}$ However, with only a few exceptions, ${ }^{62-68}$ RAFT aqueous emulsion polymerization formulations usually result in kineticallytrapped spheres. ${ }^{40,42-50,69,70}$ Nevertheless, it was considered prudent to explore higher copolymer concentrations, if only to establish the upper limit for the production of well-defined epoxy-functional spheres. Thus $\mathrm{PGMA}_{45}-\mathrm{PGlyMA}_{100}$ syntheses were conducted at $50{ }^{\circ} \mathrm{C}$ at up to $40 \% \mathrm{w} / \mathrm{w}$ solids, see Table 2 . In each case, uniform spherical nanoparticles were obtained with remarkably similar diameters and polydispersities reported by DLS (Table 2). Moreover, the molecular weight distributions obtained for these five diblock copolymers were almost identical, which suggests that relatively high copolymer concentrations are not detrimental to the preservation of the epoxy groups. However, a thin film was formed at the surface of the relatively viscous reaction mixture for the PISA synthesis conducted at $40 \% \mathrm{w} / \mathrm{w}$ solids. In principle, more efficient stirring might alleviate this problem, but this possibility was not explored in the present study. It is perhaps noteworthy that other aqueous and non-aqueous PISA formulations have also been reported to have effective upper limit copolymer concentrations of around $35-40 \% \mathrm{w} / \mathrm{w}$ solids. ${ }^{48,71}$

\section{Preparation of ABC triblock copolymers via seeded RAFT aqueous emulsion polymerization}

In principle, $\mathrm{ABC}$ triblock copolymer nanoparticles can also be prepared via seeded RAFT aqueous emulsion polymerization. $^{34,45}$ This approach could either lead to the generation of higher order morphologies (i.e. worms or framboidal vesicles $^{72-74}$ or produce onion-type nanostructures if the final copolymer morphology remains confined to kineticallytrapped spheres. ${ }^{75}$ Accordingly, PGMA $_{45}-$ PGlyMA $_{25}$ spheres were chain-extended with $n$-butyl methacrylate (BuMA). $\mathrm{PGMA}_{45}-\mathrm{PGlyMA}_{25}$ was selected for the initial diblock composition in this experiment because a PGlyMA DP of 25 is sufficient to induce nucleation but not so high as to cause incipient flocculation. ${ }^{1} \mathrm{H}$ NMR confirmed essentially full GlyMA conversion after $1.0 \mathrm{~h}$ at $50{ }^{\circ} \mathrm{C}$, and BuMA was then added via syringe, targeting a DP of 75 for the third block. After a further $3.0 \mathrm{~h}$ at $50^{\circ} \mathrm{C}$, the polymerization was quenched and analyzed by ${ }^{1} \mathrm{H}$ NMR spectroscopy and high BuMA conversion (>99\%) was achieved. In a control experiment targeting the same overall DP of 100, the corresponding statistical diblock copolymer nanoparticles were also prepared whereby the coreforming block comprised GlyMA and BuMA. DMF GPC data for the resulting $\mathrm{PGMA}_{45}-\mathrm{PGlyMA}_{25}-\mathrm{PBuMA}_{75}$ triblock copoly-

Table 2 Monomer conversions, molecular weight data and DLS diameters $\left(D_{h}\right)$ (and polydispersities) obtained for the synthesis of PGMA ${ }_{45}{ }^{-}$

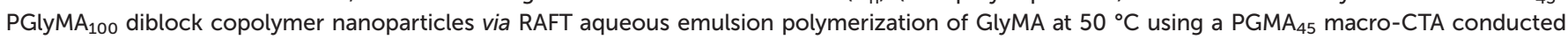
at 10 to $40 \% \mathrm{w} / \mathrm{w}$ solids

\begin{tabular}{|c|c|c|c|c|c|c|c|}
\hline Target composition & Solids $^{a}(\% \mathrm{w} / \mathrm{w})$ & Conversion $^{b}(\%)$ & $M_{\mathrm{n}}^{c}\left(\mathrm{~g} \mathrm{~mol}^{-1}\right)$ & $M_{\mathrm{w}}^{c}\left(\mathrm{~g} \mathrm{~mol}^{-1}\right)$ & $M_{\mathrm{w}} / M_{\mathrm{n}}{ }^{c}$ & $D_{\mathrm{h}}(\mathrm{nm})$ & PDI \\
\hline $\mathrm{PGMA}_{45}-\mathrm{PGlyMA}_{100}$ & 20 & $>99$ & 25400 & 31400 & 1.24 & 35 & 0.03 \\
\hline PGMA $_{45}-$ PGlyMA $_{100}$ & 35 & $>99$ & 25000 & 31000 & 1.24 & 37 & 0.05 \\
\hline $\mathrm{PGMA}_{45}-\mathrm{PGlyMA}_{100}$ & $40^{d}$ & $>99$ & 24900 & 29900 & 1.20 & 38 & 0.06 \\
\hline
\end{tabular}

${ }^{a}$ The amounts of monomer and macro-CTA were both increased in order to increase the solids content. ${ }^{b}$ Determined by ${ }^{1} \mathrm{H}$ NMR analysis in $d_{6}$-DMSO after a reaction time of $1.0 \mathrm{~h} .{ }^{c}$ Determined by gel permeation chromatography analysis using DMF eluent containing $10 \mathrm{mM}$ LiBr and calibrated with a series of near-monodisperse poly(methyl methacrylate) standards. ${ }^{d}$ Reaction mixture became viscous and a thin film formed on its surface. 
A

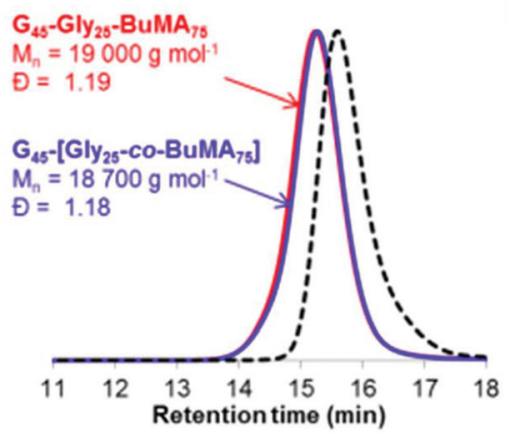

B

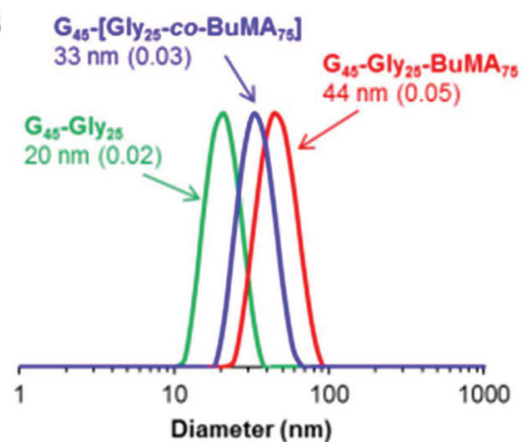

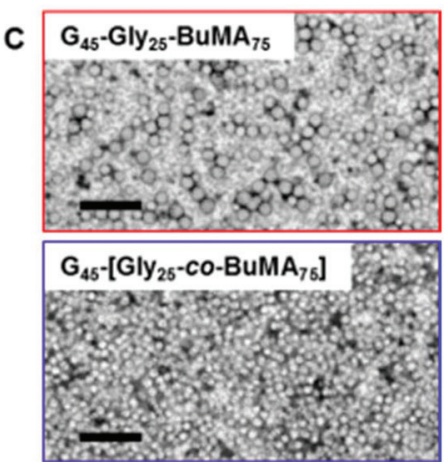

Fig. 4 (A) Overlaid GPC chromatograms recorded for PGMA $45-$ PGlyMA $_{25}-$ PBuMA $_{75}$ triblock copolymer prepared by seeded RAFT aqueous emulsion polymerization at $10 \% \mathrm{w} / \mathrm{w}$ solids. In a control experiment, the corresponding $\mathrm{PGMA}_{45}-\left[\mathrm{GlyMA}_{25}-\mathrm{CO}-\mathrm{PBuMA} \mathrm{A}_{75}\right]$ statistical diblock copolymer was also prepared by RAFT aqueous emulsion copolymerization. The original PGMA ${ }_{45} C T A$ precursor (black dotted lines; $M_{n}=12200 \mathrm{~g} \mathrm{~mol}{ }^{-1}, M_{w} / M_{n}=$ 1.16) is shown as a reference. (B) DLS intensity-average size distributions, with $D_{h}$ and PDI indicated, and (C) TEM images obtained for the PGMA ${ }_{45}{ }^{-}$ $\mathrm{PGlyMA}_{25}-\mathrm{PBuMA}_{75}$ and $\mathrm{PGMA}_{45}-\left[\mathrm{GlyMA} \mathrm{A}_{25}-\mathrm{CO}-\mathrm{PBuMA}_{75}\right.$ ] nanoparticles. Scale bars represent $200 \mathrm{~nm}$ in both images. PGMA and PGlyMA are denoted by ' $G$ ' and 'Gly' for brevity.

mer and $\mathrm{PGMA}_{45}\left[\mathrm{PGlyMA}_{25}-\mathrm{co}-\mathrm{BuMA}_{75}\right]$ statistical diblock copolymer are shown in Fig. 4A, with the GPC curve for the PGMA $_{45}$ macro-CTA precursor included as a reference. The two copolymers have essentially identical unimodal molecular weight distributions and relatively low dispersities $\left(M_{\mathrm{w}} / M_{\mathrm{n}}<\right.$ 1.20), which suggests that high blocking efficiencies and good living character were achieved in these syntheses. DLS particle size distribution curves for the same two copolymers are shown in Fig. $4 \mathrm{~B}$, with the $\mathrm{PGMA}_{45}-\mathrm{PGlyMA}_{25}$ seed nanoparticles included for reference.

Colloidally stable nanoparticles with rather narrow size distributions are obtained in both cases, but their hydrodynamic diameters are $44 \mathrm{~nm}$ and $33 \mathrm{~nm}$, respectively. This unexpected difference is also apparent in TEM images recorded for these two dispersions, see Fig. 4C. Clearly, these preliminary results are very encouraging, but higher DPs will most likely be required to drive microphase separation within such triblock copolymer spheres.

\section{Long-term stability of epoxy groups for aqueous dispersions of PGMA $_{45}$-PGlyMA 100 nanoparticles}

In order to assess whether epoxy ring-opening occurs during long-term storage at ambient temperature and $\mathrm{pH} 7$, a 10\% $\mathrm{w} / \mathrm{w}$ aqueous dispersion of $\mathrm{PGMA}_{45}-\mathrm{PGlyMA}_{100}$ nanoparticles was periodically sampled for ${ }^{1} \mathrm{H}$ NMR, GPC, and DLS analyses over twelve weeks. The DLS diameter and polydispersity remained constant over this time period (Fig. 5A), which indicates no change in the colloidal stability of the nanoparticles. However, DMF GPC analysis (Fig. 5B) provided strong evidence for intermolecular reactions occurring during long-term storage: gradual evolution of a high molecular weight shoulder led to a significant increase in both $M_{\mathrm{w}}$ and $M_{\mathrm{w}} / M_{\mathrm{n}}$. ${ }^{1} \mathrm{H}$ NMR analysis corroborated the concomitant loss of epoxy functionality (Fig. 5C). Ring-opening causes a reduction in the intensity of the two non-equivalent $\mathrm{CH}_{2}$ protons in the epoxy ring at 2.6 and $2.8 \mathrm{ppm}$, and a concomitant increase in the signal corres-
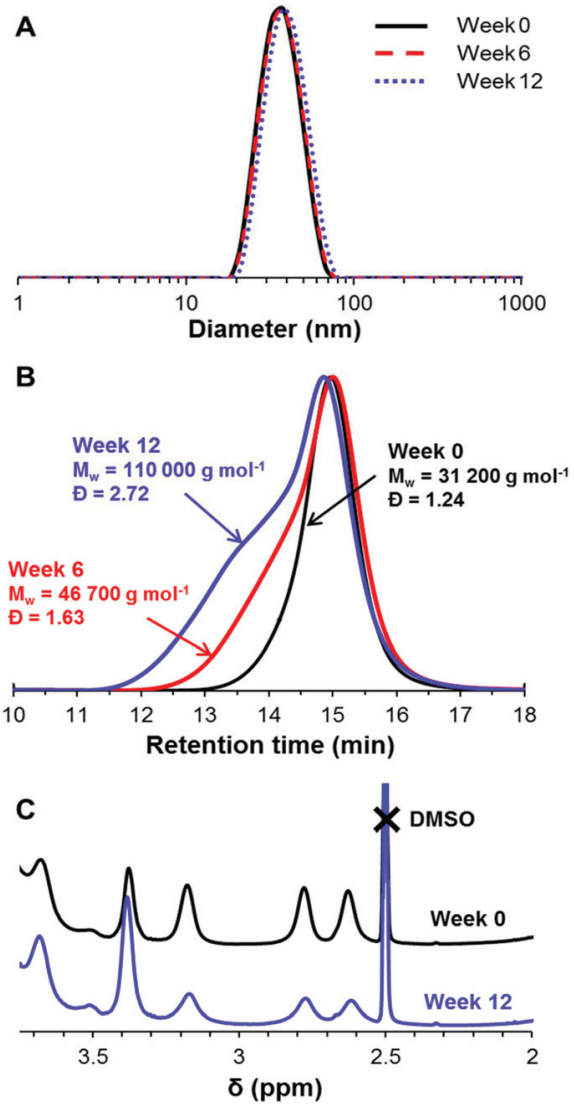

Fig. 5 Evaluation of the colloidal and chemical stability of a $10 \% \mathrm{w} / \mathrm{w}$ aqueous dispersion of $\mathrm{PGMA}_{45}-\mathrm{PGlyMA}_{100}$ nanoparticles during longterm storage at $20{ }^{\circ} \mathrm{C}$ and $\mathrm{pH}$ 7. (A) Intensity-average DLS particle size distributions and (B) DMF GPC chromatograms recorded for diluted copolymer dispersions at various time points. The former indicates excellent colloidal stability, whereas the latter suggests light branching caused by intermolecular ring-opening reactions. (C) Partial ${ }^{1} \mathrm{H}$ NMR spectra confirming the gradual loss of epoxy group functionality over time as a result of ring-opening. 
ponding to the PGMA oxymethylene protons observed at $3.4 \mathrm{ppm}$. This spectral shift enables the loss of epoxy functionality to be conveniently monitored by comparing these integrated signals to those of the methacrylate backbone protons, since the latter remain constant. After six weeks storage at $20{ }^{\circ} \mathrm{C}$, the epoxy functionality was reduced by $15 \%$, and after 12 weeks only $73 \%$ of the original epoxy groups remained intact. This hydrolytic instability may be related to the relatively high local concentration of epoxy groups within the nanoparticle cores. Since the partially-reacted epoxy groups only lead to light branching rather than highly crosslinked nanoparticles, this suggests that the majority of the ringopening events actually involve intramolecular cyclization, rather than intermolecular reactions.

Most likely, a small fraction of epoxy groups first react with water to form cis-diol units, which can then react with neighboring epoxy groups either on the same chain or on adjacent chains. In view of these observations, all of the following derivatization reactions were conducted on fresh aqueous dispersions of $\mathrm{PGMA}_{45}-\mathrm{PGlyMA}_{n}$ nanoparticles to ensure maximum epoxy functionality.

\section{Preparation of azide-functional nanoparticles}

It is well-known that epoxy groups can be ring-opened by reaction with sodium azide: ${ }^{76}$ the resulting azide-functional copolymers can be further reacted with various alkynes via Huisgen cycloaddition, a so-called 'click' reaction. ${ }^{77}$ Moreover, this chemistry is known to be highly orthogonal, hence azide derivatization significantly broadens the scope for designing bespoke functional nanoparticles for potential applications. In an initial scoping experiment, $\mathrm{PGMA}_{45}-\mathrm{PGlyMA}_{100}$ was molecularly dissolved in DMF to afford a $3.5 \% \mathrm{w} / \mathrm{w}$ solution and its epoxy groups were reacted with excess sodium azide at $20{ }^{\circ} \mathrm{C}$ in the presence of $\mathrm{NH}_{4} \mathrm{Cl}$, which acts as a coordinating salt. ${ }^{56}$
This model reaction was successful: the ${ }^{1} \mathrm{H}$ NMR spectrum recorded in $d_{6}$-DMSO for the product indicated complete loss of epoxy signals $\left(\mathrm{CH}_{2}\right.$ at 2.6 and $2.8 \mathrm{ppm}$ and $\mathrm{CH}$ at $\left.4.3 \mathrm{ppm}\right)$ while a characteristic azide stretch appeared at $2100 \mathrm{~cm}^{-1}$ in the corresponding FT-IR spectrum (Fig. 6). Subsequently, the same azide ring-opening reaction was performed on $10 \% \mathrm{w} / \mathrm{w}$ aqueous dispersions of $\mathrm{PGMA}_{45}-\mathrm{PGlyMA}_{100}$ nanoparticles at either $20^{\circ} \mathrm{C}$ or $50{ }^{\circ} \mathrm{C}$. At ambient temperature, epoxy signals (at 2.6, 2.8 and $4.3 \mathrm{ppm}$ ) were still discernible in the ${ }^{1} \mathrm{H}$ NMR spectrum even after $24 \mathrm{~h}$. However, no epoxy signals could be detected after the same time period when this reaction was run at $50{ }^{\circ} \mathrm{C}$. Moreover, such derivatizations did not require the addition of $\mathrm{NH}_{4} \mathrm{Cl}$. Visual inspection and ${ }^{1} \mathrm{H}$ NMR endgroup analysis also confirmed that cleavage of the dithiobenzoate RAFT end-groups occurred under these conditions, as indicated by the change in color (from pink to white) of the dispersion and complete loss of the aromatic proton signals at 7.9-7.5 ppm (data not shown).

\section{Core crosslinking of PGMA 45 -PGlyMA 100 nanoparticles using various diamines}

Given the high density of epoxy groups within the nanoparticle cores, diamine crosslinking should be readily achieved, see Scheme 2. Indeed, nucleophilic reaction of GlyMA residues with diamines has been utilized to covalently stabilize diblock copolymer vesicles prepared via PISA. ${ }^{52}$ Bearing in mind the long-term hydrolytic instability of the GlyMA residues discussed above, all derivatizations were conducted within 1-2 weeks of the PISA synthesis of the precursor $\mathrm{PGMA}_{45}$ PGlyMA $_{100}$ nanoparticles to ensure minimal loss of epoxy functionality. Two water-soluble diamines were investigated in this study: ethylenediamine (EDA) and bis(3-aminopropyl)-terminated poly(ethylene oxide) $\left(\mathrm{PEG}_{31} \mathrm{DA}\right)$. In the following experiments, the amount of diamine crosslinker added to the PGMA $_{45}-$ PGlyMA $_{100}$ nanoparticles is expressed in terms of an
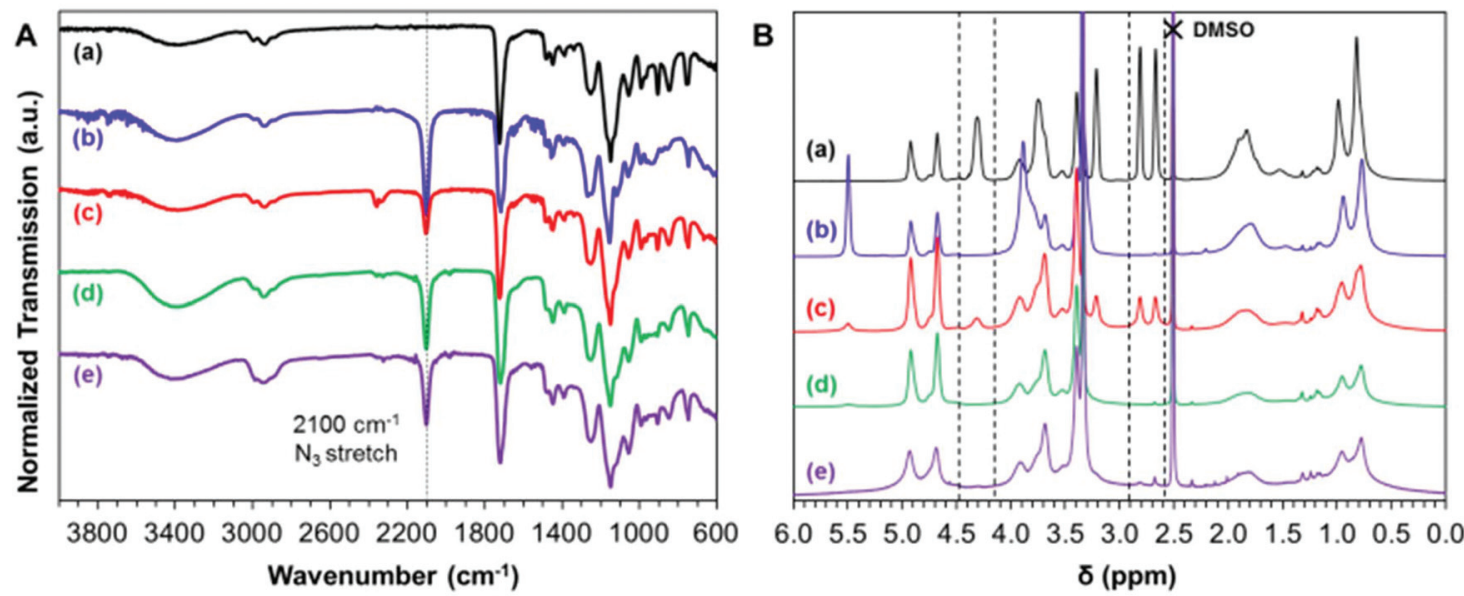

Fig. 6 (A) ATR-FTIR spectra and (B) ${ }^{1} \mathrm{H}$ NMR spectra $\left(d_{6}\right.$-DMSO) recorded for PGMA ${ }_{45}-\mathrm{PGlyMA}_{100}$ nanoparticles/chains after their reaction with excess sodium azide: (a) $\mathrm{PGMA}_{45}-\mathrm{PGlyMA}_{100}$ precursor; and (b)-(d) after reaction with 2 eq. $\mathrm{NaN}_{3}$ in the presence of 2 eq. $\mathrm{NH}_{4} \mathrm{Cl}$, (b) in $\mathrm{DMF}$ at $20{ }^{\circ} \mathrm{C}$; (c) for a $10 \% \mathrm{w} / \mathrm{w}$ aqueous dispersion at $20{ }^{\circ} \mathrm{C}$; (d) for a $10 \% \mathrm{w} / \mathrm{w}$ aqueous dispersion at $50{ }^{\circ} \mathrm{C}$; and (e) under the same conditions as (d), but in the absence of any $\mathrm{NH}_{4} \mathrm{Cl}$. 


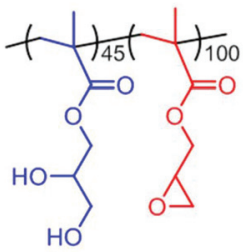

$\mathrm{H}_{2} \mathrm{~N}-\mathrm{R}-\mathrm{NH}_{2} \downarrow \begin{gathered}\text { diamine } \\ \text { crosslinking }\end{gathered}$
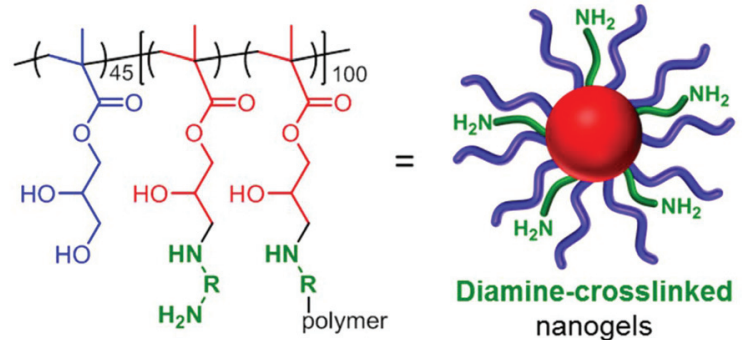

Scheme 2 Schematic representation of diamine crosslinking for 10\% $\mathrm{w} / \mathrm{w}$ aqueous dispersions of the epoxy-functional PGMA $45-\mathrm{PGlyMA}_{100}$ nanoparticles.

amine/epoxy molar ratio. Thus an amine/epoxy molar ratio of 2.0 corresponds to a diamine/epoxy molar ratio of 1.0. The desired diamine was added directly to a $10 \% \mathrm{w} / \mathrm{w}$ aqueous dispersion of the nanoparticles. Initially, DLS studies were conducted in DMF to examine the extent of crosslinking.

DMF is a good solvent for both PGMA and PGlyMA, so the linear precursor nanoparticles are molecularly dissolved in this solvent, as confirmed by GPC analysis (Fig. 3) and also the very weak light scattering observed by DLS. In contrast, successful diamine crosslinking produces appreciably swollen nanogels that cannot be dissolved in DMF (Fig. 7). The same nanogels are significantly less swollen in aqueous media, as confirmed by DLS studies conducted at $\mathrm{pH} 3-10$, and the nanogel diameters did not vary significantly when adjusting the solution $\mathrm{pH}$. EDA crosslinking at $10 \% \mathrm{w} / \mathrm{w}$ solids gave nanogels of around $37 \mathrm{~nm}$ diameter in water and $42-44 \mathrm{~nm}$ diameter in DMF, respectively. Similarly, $\mathrm{PEG}_{31} \mathrm{DA}$ crosslinked nanogels exhibited DLS diameters ranging from 50 to $59 \mathrm{~nm}$ when dispersed in DMF but only approximately 38-42 nm when analysed in dilute aqueous solution. Following crosslinking at $10 \% \mathrm{w} / \mathrm{w}$ solids, nanogels were purified by dialysis against deionized water to remove any unreacted diamine, followed by dilution with $d_{6}$-DMSO for ${ }^{1} \mathrm{H}$ NMR analysis of the residual epoxy protons at 2.6 and $2.8 \mathrm{ppm}$. No epoxy signals could be detected in any of the EDA-crosslinked nanogels (see Fig. S5 $\dagger$ ), indicating the formation of densely crosslinked nanogels even when using relatively low amine/epoxy molar ratios. However, residual epoxy signals could be detected for the $\mathrm{PEG}_{31} \mathrm{DA}$-crosslinked nanogels when using amine/epoxy molar ratios of 0.1 or 0.25 (Fig. S6 $\dagger$ ). Moreover, using higher $\mathrm{PEG}_{31} \mathrm{DA}$ concentrations increases the extent of crosslinking of the nanogels.
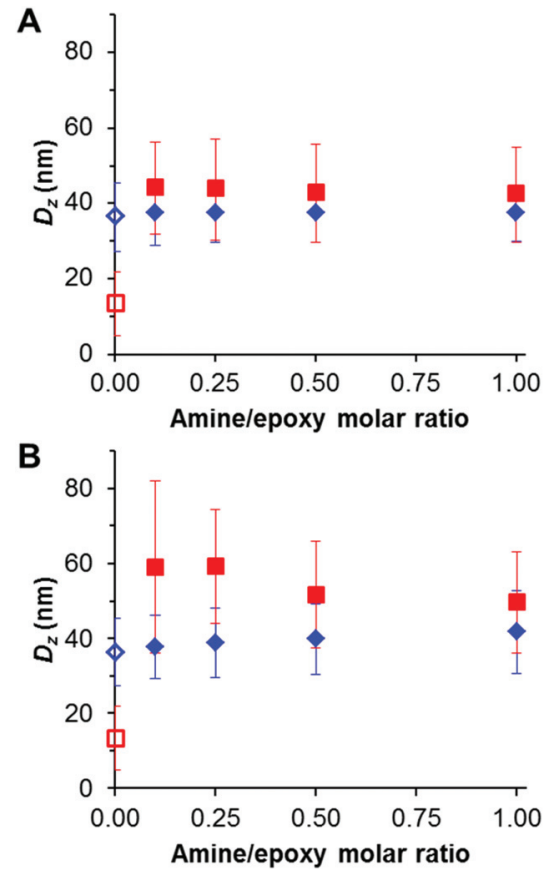

Fig. 7 DLS analysis of $\mathrm{PGMA}_{45}-\mathrm{PGlyMA}_{100}$ nanoparticles crosslinked at $10 \% \mathrm{w} / \mathrm{w}$ solids using either (A) EDA or (B) $\mathrm{PEG}_{31}-\mathrm{DA}$ at $20^{\circ} \mathrm{C}$, followed by dilution to $0.1 \% \mathrm{w} / \mathrm{w}$ solids using either deionized water (blue diamonds) or DMF (red squares). The corresponding empty symbols represent the original $\mathrm{PGMA}_{45}-\mathrm{PGlyMA}_{100}$ nanoparticles prior to diamine crosslinking. The error bars indicate the standard deviation in the DLS particle size distributions, rather than the experimental error.

Freeze-dried nanogels were also analyzed by nitrogen microanalysis, see Table 3. Increasing the amine/epoxy molar ratio used to prepare the EDA-crosslinked nanogels led to higher nitrogen contents, as expected. It is worth noting that the theoretical values shown in Table 3 were calculated assuming that each amine group reacts just once with an epoxy group (i.e. every diamine reacts with just two epoxy groups to form two secondary amines). However, in principle each primary amine can react with two epoxy groups; thus the first epoxy group reacts to produce a secondary amine, which then reacts with the second epoxy group to form a tertiary amine. Furthermore, the hydroxyl group produced via epoxy ringopening can also react, albeit more slowly, with other epoxy groups. Both these 'side reactions' should lower the nitrogen content of the resulting nanogels and may well be more prevalent when using the $\mathrm{PEG}_{31} \mathrm{DA}$ crosslinker. This is because this polymeric diamine diffuses more slowly into the nanoparticle cores than EDA, which should allow more time for the initially-formed secondary amines to react with neighboring epoxy groups. FT-IR studies (Fig. S7 and S8†) did not corroborate the formation of secondary amine groups. However, the $\mathrm{C}-\mathrm{O}$ stretch at around $1100 \mathrm{~cm}^{-1}$ became broader when using higher amine/epoxy molar ratios for the synthesis of the PEG $_{31}$ DA-crosslinked nanogels, suggesting successful incorporation of the PEG chains, see Fig. S8. $\dagger$ 
Table 3 Nitrogen microanalyses obtained before and after diamine crosslinking of $10 \% \mathrm{w} / \mathrm{w}$ aqueous dispersions of $\mathrm{PGMA}_{45}-\mathrm{PGlyMA}_{100}$ spherical nanoparticles at $20{ }^{\circ} \mathrm{C}$ using either ethylenediamine (EDA) or bis(3-aminopropyl)-terminated poly(ethylene oxide) ( $\left.P G_{31} D A\right)$

\begin{tabular}{llll}
\hline & & \multicolumn{2}{l}{$\mathrm{N}$ content $(\%)$} \\
\cline { 3 - 4 } Diamine type & Amine/epoxy molar ratio & Theory & Exp \\
\hline Original sample & 0.00 & 0.06 & $0.10^{a}$ \\
& & & \\
EDA & 0.10 & 0.70 & 0.76 \\
EDA & 0.25 & 1.63 & 1.05 \\
EDA & 0.50 & 3.09 & 1.25 \\
EDA & 1.00 & 5.74 & 1.49 \\
& & & \\
PEG $_{31}$ DA & 0.10 & 0.53 & $0.02^{a}$ \\
PEG $_{31}$ DA & 0.25 & 0.90 & $0.24^{a}$ \\
PEG $_{31}$ DA & 0.50 & 1.21 & 0.36 \\
PEG $_{31}$ DA & 1.00 & 1.46 & 0.66 \\
${ }^{a}$ Below the instrument detection limit of $0.3 \%$. & \\
& & &
\end{tabular}

\section{Aqueous electrophoretic behavior of crosslinked nanogels}

Diamine crosslinking also conferred cationic character on the nanogels owing to protonation of pendent unreacted primary amine groups (and also the newly-formed secondary amine groups). Zeta potential $v s$. $\mathrm{pH}$ curves were constructed for two types of crosslinked nanogels prepared using an amine/epoxy molar ratio of 1.0, see Fig. 8. These dispersions possessed the highest nitrogen contents as judged by elemental microanalysis and hence were expected to be the most cationic in nature.

The original linear $\mathrm{PGMA}_{45}-\mathrm{PGlyMA}_{100}$ particles exhibit negative zeta potentials of between -2 and $-6 \mathrm{mV}$ across the whole $\mathrm{pH}$ range. This weakly anionic character is attributed to a minor fraction of carboxylic acid groups located on some of the PGMA stabilizer chain-ends, because this macro-CTA was prepared using an anionic azo initiator (ACVA). In contrast, the EDA-crosslinked nanogel has an isoelectric point of approximately $\mathrm{pH} 9.7$ and becomes moderately cationic at lower $\mathrm{pH}$,

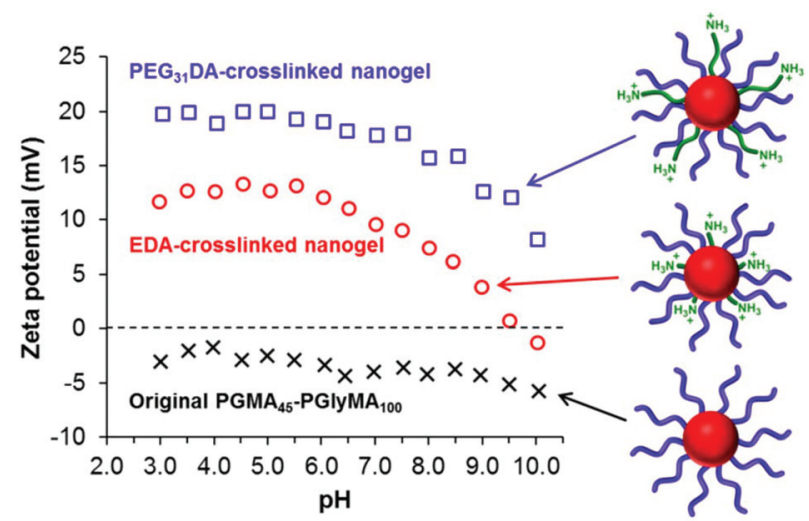

Fig. 8 Zeta potential vs. $\mathrm{pH}$ curves recorded for $\mathrm{PGMA}_{45}-\mathrm{PGlyMA}_{100}$ nanogels crosslinked using either $\mathrm{PEG}_{31} \mathrm{DA}$ (blue squares) or EDA (red circles) at an amine/epoxy molar of 1.0. The data set obtained for the original linear $\mathrm{PGMA}_{45}-\mathrm{PGlyMA}_{100}$ diblock copolymer nanoparticles is also shown for comparison (black crosses). with a maximum zeta potential of $+13 \mathrm{mV}$ at around $\mathrm{pH}$ 4-6. Interestingly, the $\mathrm{PEG}_{31} \mathrm{DA}$-crosslinked nanogel exhibited a positive zeta potential of at least $+10 \mathrm{mV}$ across the whole $\mathrm{pH}$ range, with a maximum zeta potential of $+20 \mathrm{mV}$ obtained a $\mathrm{pH}$ of 3-6. The enhanced cationic nature of this latter nanogel is attributed to the long-chain nature of the $\mathrm{PEG}_{31} \mathrm{DA}$ crosslinker, which enables pendent primary amine groups not involved in epoxy ring-opening reactions to protrude further into the $\mathrm{PGMA}_{45}$ stabilizer layer and hence exert a stronger influence over the electrophoretic behavior of the nanogel. These cationic nanogels can be compared to sterically-stabilized spherical nanoparticles prepared via PISA by Semsarilar et al. ${ }^{78}$ who statistically copolymerized a small amount of a quaternized methacrylic monomer with GMA to prepare a weakly cationic stabilizer block. In a different approach, Williams et $a .^{79}$ utilized a binary mixture of cationic and nonionic stabilizer blocks to prepare primary amine-functionalized diblock copolymer nano-objects with similar electrophoretic behavior via RAFT aqueous dispersion polymerization.

Clearly, the PISA syntheses reported herein provide multiple opportunities for the design and convenient synthesis of welldefined cationic nanoparticles. Moreover, primary amine functionality can be introduced without utilizing relatively expensive primary amine-based vinyl monomers such as 2-aminoethyl methacrylate. ${ }^{79}$

\section{Conclusions}

Well-defined epoxy-functional diblock copolymer nanoparticles can be conveniently prepared via RAFT aqueous emulsion polymerization of glycidyl methacrylate using a water-soluble poly(glycerol monomethacrylate) precursor as the stabilizer block. Optimization of the reaction conditions ensured that essentially all of the epoxy groups were retained throughout the polymerization. More specifically, polymerizations were performed at $\mathrm{pH} 4-7$ and more than 99\% conversion was achieved within $1 \mathrm{~h}$ at $50{ }^{\circ} \mathrm{C}$, with DMF GPC analyses indicating relatively low dispersities $\left(M_{\mathrm{w}} / M_{\mathrm{n}}<1.30\right)$. However, longer reaction times led to significantly broader molecular weight distributions because the hydrolytic instability of the epoxy groups leads to latent branching. Colloidally stable diblock copolymer nanoparticles could be obtained at up to $35 \% \mathrm{w} / \mathrm{w}$ solids, but only when targeting relatively short coreforming blocks (DP $\leq 100$ ). Targeting longer PGlyMA chains led to nanoparticle flocculation. Well-defined triblock copolymers could also be prepared via seeded RAFT aqueous emulsion polymerization, which extends the scope of this new PISA formulation. Gradual loss of epoxy functionality was observed during long-term storage at $20{ }^{\circ} \mathrm{C}$, but fresh aqueous dispersions of $\mathrm{PGMA}_{45}-\mathrm{PGlyMA}_{100}$ nanoparticles could be derivatized via various nucleophilic ring-opening reactions. For example, addition of various diamines led to the formation of cationic core-crosslinked nanogels that remained stable when subjected to a solvent challenge. In contrast, the original linear diblock copolymer nanoparticles dissolved fully in a good 
solvent for both blocks (DMF). This study demonstrates that glycidyl methacrylate can be utilized for RAFT aqueous emulsion polymerization provided that appropriate care is taken to optimize the reaction conditions in order to minimize the well-known side-reactions associated with this highly versatile monomer.

\section{Acknowledgements}

EPSRC is acknowledged for a Platform grant (EP/J007846/1). The European Research Council is thanked for a five-year Advanced Investigator grant for S. P. A. (PISA 320372). GEO Specialty Chemicals (Hythe, UK) is thanked for donation of the GMA monomer.

\section{References}

1 P. F. Cañamero, J. L. de la Fuente, E. L. Madruga and M. Fernández-García, Macromol. Chem. Phys., 2004, 205, 2221-2228.

2 R. B. Grubbs, J. M. Dean, M. E. Broz and F. S. Bates, Macromolecules, 2000, 33, 9522-9534.

3 J. Zhu, D. Zhou, X. Zhu and G. Chen, J. Polym. Sci., Part A: Polym. Chem., 2004, 42, 2558-2565.

4 H. Yin, H. Zheng, L. Lu, P. Liu and Y. Cai, J. Polym. Sci., Part A: Polym. Chem., 2007, 45, 5091-5102.

5 M. Benaglia, A. Alberti, L. Giorgini, F. Magnoni and S. Tozzi, Polym. Chem., 2013, 4, 124-132.

6 O. I. Strube, L. Nothdurft, Z. Abisheva and G. SchmidtNaake, Macromol. Chem. Phys., 2012, 213, 1274-1284.

7 Q.-L. Li, W.-X. Gu, H. Gao and Y.-W. Yang, Chem. Commun., 2014, 50, 13201-13215.

8 S. D. Kimmins, P. Wyman and N. R. Cameron, Polymer, 2014, 55, 416-425.

9 H. Li, X. Zhang, X. Zhang, K. Wang, Q. Zhang and Y. Wei, J. Mater. Chem. B, 2015, 3, 1193-1197.

10 N. Ezaki, Y. Watanabe and H. Mori, Langmuir, 2015, 31, 11399-11408.

11 M. J. Beněs, D. Horák and F. Svec, J. Sep. Sci., 2005, 28, 1855-1875.

12 P. Misra, J. M. Chitanda, A. K. Dalai and J. Adjaye, Chem. Eng. J., 2016, 295, 109-118.

13 A. B. Nastasović, B. M. Ekmeščić, Z. P. Sandić, D. V. Ranđelović, M. Mozetič, A. Vesel and A. E. Onjia, Appl. Surf. Sci., 2016, 385, 605-615.

14 S. Huš, M. Kolar and P. Krajnc, J. Chromatogr., A, 2016, 1437, 168-175.

15 S. Ghosh and N. Krishnamurti, Eur. Polym. J., 2000, 36, 2125-2131.

16 J. A. Kling and H. J. Ploehn, J. Polym. Sci., Part A: Polym. Chem., 1995, 33, 1107-1118.

17 E. Žůrková, K. Bouchal, D. Zden̆ková, Z. Pelzbauer, F. Švec, J. Kálal and H. G. Batz, J. Polym. Sci., Part A: Polym. Chem., 1983, 21, 2949-2960.
18 W. C. Zhang, Y. Sun and L. Zhang, Ind. Eng. Chem. Res., 2015, 54, 6480-6488.

19 J. B. Tan, L. L. Fu, X. C. Zhang, Y. H. Bai and L. Zhang, J. Mater. Sci., 2016, 51, 9455-9471.

20 H. Hlídková, I. Kotelnikov, O. Pop-Georgievski, V. Proks and D. Horák, Macromolecules, 2017, 50, 1302-1311.

21 Y. A. Liu, K. Jiang, Y. H. Ma, L. Y. Liu and W. T. Yang, Polym. Chem., 2016, 7, 2728-2739.

22 R. X. Liu, A. H. Milani, T. J. Freemont and B. R. Saunders, Soft Matter, 2011, 7, 4696-4704.

23 H. Zhou, X. Wang, J. Tang and Y. W. Yang, Polym. Chem., 2016, 7, 2171-2179.

24 X. L. Fan, X. J. Jia, H. P. Zhang, B. L. Zhang, C. M. Li and Q. Y. Zhang, Langmuir, 2013, 29, 11730-11741.

25 S. Edmondson and W. T. S. Huck, J. Mater. Chem., 2004, 14, 730-734.

26 R. Barbey and H.-A. Klok, Langmuir, 2010, 26, 18219-18230.

27 Y. Mai and A. Eisenberg, Chem. Soc. Rev., 2012, 41, 59695985.

28 B. Charleux, G. Delaittre, J. Rieger and F. D'Agosto, Macromolecules, 2012, 45, 6753-6765.

29 P. B. Zetterlund, S. C. Thickett, S. Perrier, E. Bourgeat-Lami and M. Lansalot, Chem. Rev., 2015, 115, 9745-9800.

30 S. L. Canning, G. N. Smith and S. P. Armes, Macromolecules, 2016, 49, 1985-2001.

31 J. Jennings, G. He, S. M. Howdle and P. B. Zetterlund, Chem. Soc. Rev., 2016, 45, 5055-5084.

32 M. J. Derry, L. A. Fielding and S. P. Armes, Prog. Polym. Sci., 2016, 52, 1-18.

33 C. J. Ferguson, R. J. Hughes, B. T. T. Pham, B. S. Hawkett, R. G. Gilbert, A. K. Serelis and C. H. Such, Macromolecules, 2002, 35, 9243-9245.

34 C. J. Ferguson, R. J. Hughes, D. Nguyen, B. T. T. Pham, R. G. Gilbert, A. K. Serelis, C. H. Such and B. S. Hawkett, Macromolecules, 2005, 38, 2191-2204.

35 D. E. Ganeva, E. Sprong, H. de Bruyn, G. G. Warr, C. H. Such and B. S. Hawkett, Macromolecules, 2007, 40, 6181-6189.

36 N. J. Warren and S. P. Armes, J. Am. Chem. Soc., 2014, 136, 10174-10185.

37 C. K. Poon, O. Tang, X.-M. Chen, B. T. T. Pham, G. Gody, C. A. Pollock, B. S. Hawkett and S. Perrier, Biomacromolecules, 2016, 17, 965-973.

38 A. R. Shirin-Abadi, P. G. Jessop and M. F. Cunningham, Macromol. React. Eng., 2017, 11, 1600035.

39 C. N. Urbani and M. J. Monteiro, Macromolecules, 2009, 42, 3884-3886.

40 I. Chaduc, W. J. Zhang, J. Rieger, M. Lansalot, F. D’Agosto and B. Charleux, Macromol. Rapid Commun., 2011, 32, 1270-1276.

41 J. Rieger, Macromol. Rapid Commun., 2015, 36, 1458-1471.

42 W. J. Zhang, F. D'Agosto, P. Y. Dugas, J. Rieger and B. Charleux, Polymer, 2013, 54, 2011-2019.

43 L. Carlsson, A. Fall, I. Chaduc, L. Wagberg, B. Charleux, E. Malmstrorn, F. D’Agosto, M. Lansalot and A. Carlmark, Polym. Chem., 2014, 5, 6076-6086. 
44 F. L. Hatton, M. Ruda, M. Lansalot, F. D'Agosto, E. Malmstrom and A. Carlmark, Biomacromolecules, 2016, 17, 1414-1424.

45 I. Chaduc, M. Girod, R. Antoine, B. Charleux, F. D'Agosto and M. Lansalot, Macromolecules, 2012, 45, 5881-5893.

46 J. Rieger, F. Stoffelbach, C. Bui, D. Alaimo, C. Jerome and B. Charleux, Macromolecules, 2008, 41, 4065-4068.

47 J. Engstrom, F. L. Hatton, L. Wagberg, F. D’Agosto, M. Lansalot, E. Malmstrom and A. Carlmark, Polym. Chem., 2017, 8, 1061-1073.

48 V. J. Cunningham, A. M. Alswieleh, K. L. Thompson, M. Williams, G. J. Leggett, S. P. Armes and O. M. Musa, Macromolecules, 2014, 47, 5613-5623.

49 B. Akpinar, L. A. Fielding, V. J. Cunningham, Y. Ning, O. O. Mykhaylyk, P. W. Fowler and S. P. Armes, Macromolecules, 2016, 49, 5160-5171.

50 L. H. Guo, Y. J. Pang, T. Qiu, Y. Meng and X. Y. Li, Polymer, 2014, 55, 4601-4610.

51 L. P. D. Ratcliffe, A. J. Ryan and S. P. Armes, Macromolecules, 2013, 46, 769-777.

52 P. Chambon, A. Blanazs, G. Battaglia and S. P. Armes, Langmuir, 2012, 28, 1196-1205.

53 N. J. W. Penfold, Y. Ning, P. Verstraete, J. Smets and S. P. Armes, Chem. Sci., 2016, 7, 6894-6904.

54 J. R. Lovett, L. P. D. Ratcliffe, N. J. Warren, S. P. Armes, M. J. Smallridge, R. B. Cracknell and B. R. Saunders, Macromolecules, 2016, 49, 2928-2941.

55 J. Tan, D. Liu, C. Huang, X. Li, J. He, Q. Xu and L. Zhang, Macromol. Rapid Commun., 2017, DOI: 10.1002/ marc.201700195.

56 L. Esser, N. P. Truong, B. Karagoz, B. A. Moffat, C. Boyer, J. F. Quinn, M. R. Whittaker and T. P. Davis, Polym. Chem., 2016, 7, 7325-7337.

57 A. Blanazs, A. J. Ryan and S. P. Armes, Macromolecules, 2012, 45, 5099-5107.

58 V. J. Cunningham, M. J. Derry, L. A. Fielding, O. M. Musa and S. P. Armes, Macromolecules, 2016, 49, 4520-4533.

59 N. J. Warren, O. O. Mykhaylyk, A. J. Ryan, M. Williams, T. Doussineau, P. Dugourd, R. Antoine, G. Portale and S. P. Armes, J. Am. Chem. Soc., 2015, 137, 1929-1937.

60 I. Bannister, N. C. Billingham, S. P. Armes, S. P. Rannard and P. Findlay, Macromolecules, 2006, 39, 7483-7492.

61 Y. Li and S. P. Armes, Macromolecules, 2005, 38, 8155-8162.
62 S. Boisse, J. Rieger, K. Belal, A. Di-Cicco, P. Beaunier, M. H. Li and B. Charleux, Chem. Commun., 2010, 46, 19501952.

63 S. Boisse, J. Rieger, G. Pembouong, P. Beaunier and B. Charleux, J. Polym. Sci., Part A: Polym. Chem., 2011, 49, 3346-3354.

64 X. W. Zhang, S. Boisse, W. J. Zhang, P. Beaunier, F. D'Agosto, J. Rieger and B. Charleux, Macromolecules, 2011, 44, 4149-4158.

65 W. J. Zhang, F. D'Agosto, O. Boyron, J. Rieger and B. Charleux, Macromolecules, 2011, 44, 7584-7593.

66 J. L. de la Haye, X. W. Zhang, I. Chaduc, F. Brunel, M. Lansalot and F. D'Agosto, Angew. Chem., Int. Ed., 2016, 55, 3739-3743.

67 A. A. Cockram, T. J. Neal, M. J. Derry, O. O. Mykhaylyk, N. S. J. Williams, M. W. Murray, S. N. Emmett and S. P. Armes, Macromolecules, 2017, 50, 796-802.

68 W. J. Zhang, F. D'Agosto, O. Boyron, J. Rieger and B. Charleux, Macromolecules, 2012, 45, 4075-4084.

69 I. Chaduc, A. Crepet, O. Boyron, B. Charleux, F. D’Agosto and M. Lansalot, Macromolecules, 2013, 46, 6013-6023.

70 I. Chaduc, E. Reynaud, L. Dumas, L. Albertin, F. D’Agosto and M. Lansalot, Polymer, 2016, 106, 218-228.

71 S. Binauld, L. Delafresnaye, B. Charleux, F. D'Agosto and M. Lansalot, Macromolecules, 2014, 47, 3461-3472.

72 P. Chambon, A. Blanazs, G. Battaglia and S. P. Armes, Macromolecules, 2012, 45, 5081-5090.

73 C. J. Mable, N. J. Warren, K. L. Thompson, O. O. Mykhaylyk and S. P. Armes, Chem. Sci., 2015, 6, 6179-6188.

74 C. J. Mable, K. L. Thompson, M. J. Derry, O. O. Mykhaylyk, B. P. Binks and S. P. Armes, Macromolecules, 2016, 49, 7897-7907.

75 Y. Kitayama, M. Yorizane, Y. Kagawa, H. Minami, P. B. Zetterlund and M. Okubo, Polymer, 2009, 50, 3182-3187.

76 M. W. Jones, L. Otten, S. J. Richards, R. Lowery, D. J. Phillips, D. M. Haddleton and M. I. Gibson, Chem. Sci., 2014, 5, 1611-1616.

77 J.-F. Lutz, Angew. Chem., Int. Ed., 2007, 46, 1018-1025.

78 M. Semsarilar, V. Ladmiral, A. Blanazs and S. P. Armes, Langmuir, 2013, 29, 7416-7424.

79 M. Williams, N. J. W. Penfold, J. R. Lovett, N. J. Warren, C. W. I. Douglas, N. Doroshenko, P. Verstraete, J. Smets and S. P. Armes, Polym. Chem., 2016, 7, 3864-3873. 